\title{
Effects of chronic unpredictable stress on intestinal morphology in Wistar rats
}

\author{
Ufuk Çorumlu $^{1}$ (D), Osman Özcan Aydın² (D), Emel Ulupınar ${ }^{1,2}$ (D) \\ ${ }^{1}$ Department of Anatomy, Faculty of Medicine, Eskişebir Osmangazi University, Eskişehir, Turkey \\ ${ }^{2}$ Interdisciplinary Neuroscience Department, Eskişehir Osmangazi University, Eskişehir, Turkey
}

\begin{abstract}
Objectives: Stressful events might cause immune dysfunction and trigger various disorders. Adverse effects of acute or chronic stress exposure on the gastrointestinal system have been shown previously in several studies. In this experimental study, we used chronic unpredictable stress (CUS) paradigm to better mimic effects of the intermittent exposure to daily life stress and investigated the morphometric alterations occurring in the small intestines of rats.

Methods: Male Wistar rats were randomly divided into stress and control groups ( $n=8$, each). While stress group was subjected to chronic unpredictable stress protocol for 21 days, control group remained undisturbed. Intestinal tissue samples were obtained from two different regions; one was 3-6 cm away from the pylorus and the other one 3-6 cm prior to the ileocaecal valve. Tissue sections were obtained from paraffin blocks at the thickness of 3 micrometers and stained with hematoxylin-eosin (HE) or periodic acid-Shiff (PAS). The lengths of villi were measured from the basal membrane to the top of the villus. The ratio of degranulating and non-degranulating mast cells per unit area were estimated by point counting method.

Results: The mean villi length in the stress group were significantly higher $(p<0.01)$ than those of the control group. Degranulation to non-degranulation ratio of the mast cells were $40 \%$ and $54 \%$ in the control and stress groups, respectively.

Conclusion: Animals exposed to chronic unpredictable stress protocol displayed a significant elongation in the villi of small intestines and an increase in the number of degranulating mast cells in the intestinal mucosa. Since activation of mast cells causes releasing of various chemical mediators and growth factors, it is plausible that stressed animals developed an adaptation mechanism to enhance the capacity for absorption and digestion per unit length of the guts.
\end{abstract}

Keywords: chronic unpredictable stress; gastrointestinal system; mast cell; villus length

Anatomy 2019;13(1):27-32 @2019 Turkish Society of Anatomy and Clinical Anatomy (TSACA)

\section{Introduction}

Stress is a usual part of daily living; however, if its level exceeds the adaptive capacity of an individual, it might predispose to illnesses in multiple systems including the gastrointestinal organs. ${ }^{[1,2]}$ It has been shown that diverse stressors have a major influence on the gastrointestinal secretion, motility, epithelial permeability, and inflammation. ${ }^{[3]}$ Also, in different animal models, stress exposure leads to intestinal pathology such as increased ion secretion, macromolecular permeability, microscopic inflammation, visceral hypersensitivity, dysmotility, and even bacterial penetration. ${ }^{[4]}$

The chronic unpredictable stress (CUS) model is originally used to study mechanisms underlying the stress response. ${ }^{[5]}$ One of the main advantages of this protocol is better imitating the intermittent exposure to daily life stress. It also has a greater face validity than the other animal models of stress exposure. ${ }^{[6]}$ Multiple experimental observations have suggested that endogenous gastrointestinal secretions and structural changes are important mechanisms for adaptation to stress exposure. Among them, mast cells have a special importance since they are associated with diverse modulatory effects in innate and adaptive immunity. ${ }^{[7]}$ The mast cells of rodents and humans are numerous, and if grouped together they would make an organ equal to the size of the spleen. ${ }^{[8]}$ Upon activation, mast cells can release a variety of chemical mediators stored in their secretory granules into the 
extracellular environment within minutes, a process known as degranulation. ${ }^{[0]}$ Therefore, in this study, we used CUS model to investigate the morphological changes in the small intestines of rats and specifically aimed to analyze alterations in the mast cells located in the guts.

\section{Materials and Methods}

Healthy male Wistar rats were obtained from the breeding colony at the Eskişehir Osmangazi University Animal Care Facility and maintained under constant temperature $\left(21^{\circ} \mathrm{C}\right)$ and light $(12: 12 \mathrm{~h} \mathrm{light/dark}$ cycle $)$ conditions. Experimental procedures were performed in accordance with protocols approved by the Institutional Animal Usage Committee (Protocol number: 2016/526). Chronic unpredictable stress (CUS) model was applied to the stress group $(n=8)$. During 21 days, rats were randomly exposed to stressors such as change of dark / light cycle, 45 degree tilted cage, wet bedding, crowded conditions, cold environment, predator odor, isolation in steel cage, exposure to bright light, water and food deprivation; two times a day (Table 1). Any intervention was not applied to the animals in the control group $(\mathrm{n}=8)$ except weekly body weighting. At the end of 21th day, rats were perfused intracardiacally with neutral phosphate buffer saline $(\mathrm{pH}=7.4)$ and then with $4 \%$ paraformaldehyde solution.

Intestinal tissue samples were obtained from two different regions; $3-6 \mathrm{~cm}$ away from pylorus, $3-6 \mathrm{~cm}$ prior to the ileocaecal valve. They were dehydrated, cleared, and then embedded in paraffin; $3 \mu \mathrm{m}$ thick sections were obtained from each sample. The sections were mounted on slides, dried, and subsequently deparaffinized in three changes of xylol and rehydrated in three changes of $95 \%$ ethyl alcohol and distilled water. Histomorphological assessment was carried out by staining the sections with
Table 1

The list and the application time of each stressor. Two of the stressors were applied randomly per day to each rat.

\begin{tabular}{lc}
\hline Stressor type & Application duration \\
\hline Change of dark / light cycle & $12 / 12 \mathrm{~h}$ \\
45 degree tilted cage & $8 \mathrm{~h}$ \\
Wet bedding & $8 \mathrm{~h}$ \\
Crowded conditions & $8 \mathrm{~h}$ \\
Cold environment & $15 \mathrm{~min}$ \\
Predator odor & $15 \mathrm{~min}$ \\
Isolation in steel cage & $8 \mathrm{~h}$ \\
Exposure to bright light & $12 \mathrm{~h}$ \\
Water deprivation & $4 \mathrm{~h}$ \\
Food deprivation & $8 \mathrm{~h}$ \\
\hline
\end{tabular}

hematoxylin-eosin (HE), and periodic acid-Shiff (PAS) staining was used for mast cell counting. The sections were then rinsed and blotted carefully, dehydrated through 95\% ethanol, absolute alcohol and xylene. For each animal, 10 sections in which the villi can be identified clearly were selected for the morphometric analyses. Measurements were done in at least 10 different areas from each section. Villi lengths were measured from the basal membrane to the top of the villus in a straight line by the StereoInvestigator software (Version 11; Microbrightfield Inc., Williston, VT, USA). A total of 1600 villi lengths were measured from stress and control groups. The number of non-degranulating and degranulating mast cells were estimated with point counting method using a grid. Systematic random sampling method was applied in the selection of areas under the high power objectives and both degranulating and nondegranulating mast cells per unit area were counted on 10 different sections obtained from each rat (Figure 1).

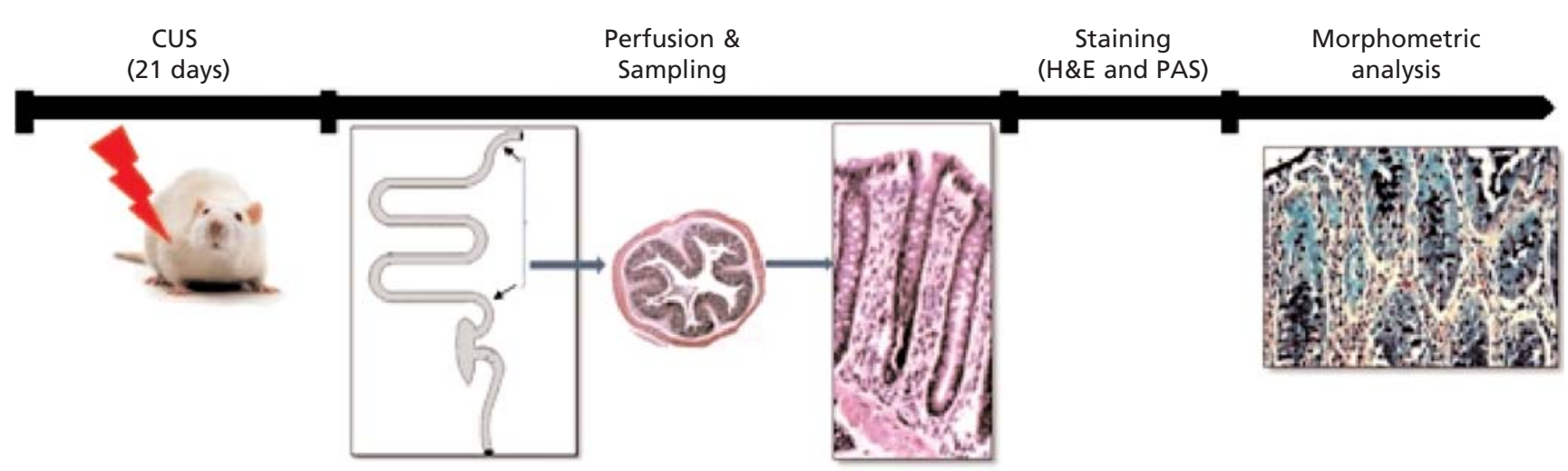

Figure 1. Experimental design. [Color figure can be viewed in the online issue, which is available at www.anatomy.org.tr] 

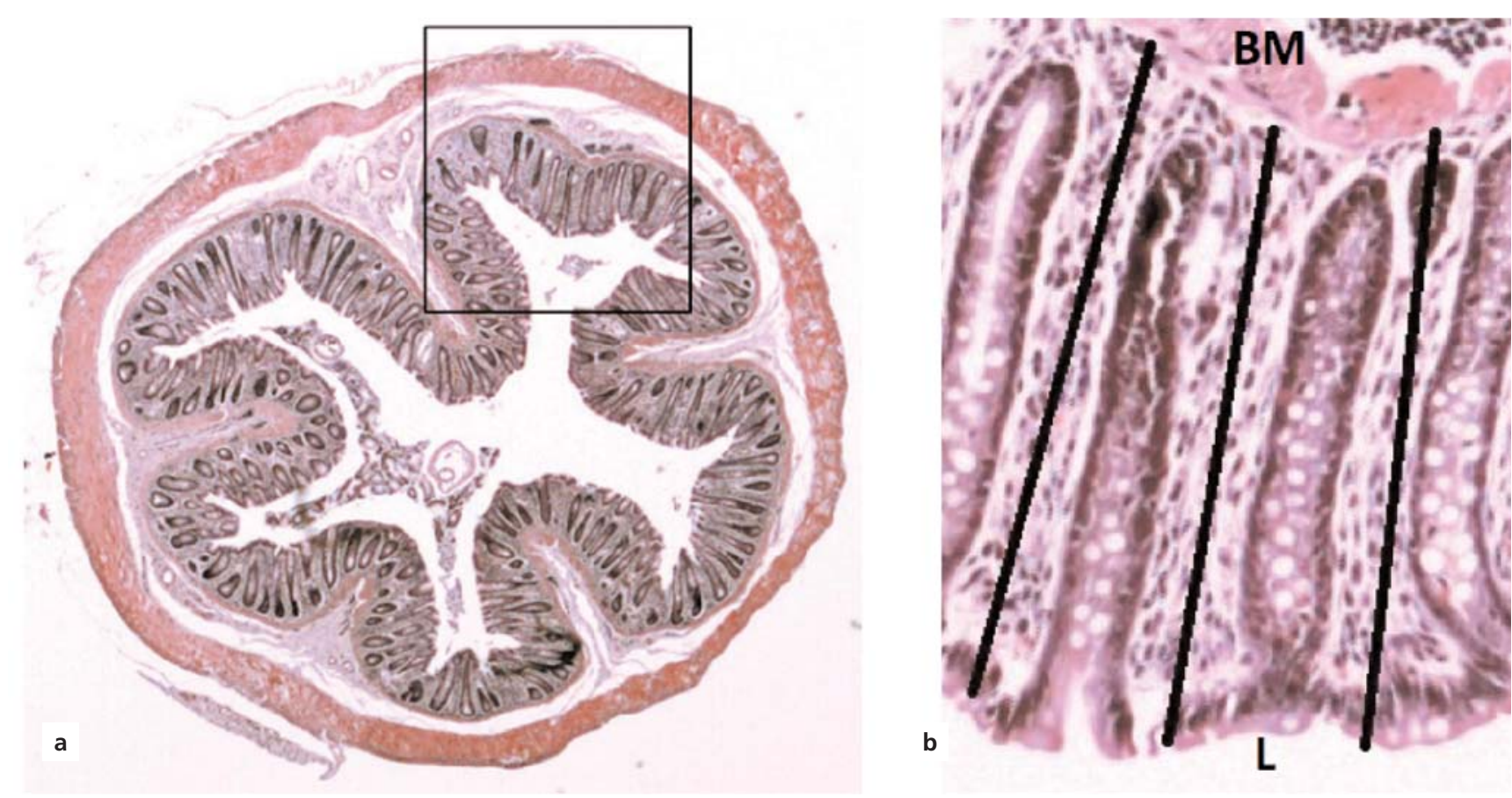

Figure 2. Photomicrographs obtained from the small intestinal tissue. (a) Cross sectional view of small intestine (10x) is shown; (b) High power view of outlined area (black box). Black straight lines in B are used for the villus length measurements. BM: basal membrane; L: lumen. [Color figure can be viewed in the online issue, which is available at www.anatomy.org.tr]

\section{Results}

The cross sections obtained from the intestinal tissue of animals were stained and examined under the light microscopy. In both control and stress groups, the integrity of the intestinal mucosa was maintained and there were no irregularities in the glandular structures (Figure 2a). No inflammatory infiltration or ulceration was seen in the intestinal wall. Analysis at higher magnifications allowed the measurement of the villus length, from the basal membrane to the tip of the villus (Figure 2b). The mean length of the villi was $292.4 \mu \mathrm{m}$ and 229.1 $\mu \mathrm{m}$ in the stress and control groups, respectively; significantly higher $(\mathrm{p}<0.01)$ in the stress group compared to those of controls (Figure 3). At the same time, a significant increase in the density of mast cells was detected in the stressed group. Degranulating mast cells were detectable in the histological sections stained by PAS method with numerous extracellular meta-chromatic granules. On the other hand, non-degranulating mast cells were characterized by rich intracytoplasmic granule contents. Average density of degranulating and nondegranulating mast cells were estimated by using a counting grid. In the high power view of degranulating mast cells, pink-purple color granules were easily discernable (Figure 4). When degranulation to nondegranulation ratio of mast cells were calculated by using the percentages of cells per unit area, the control group had lower (40\%) degranulating mast cells than the stress group (54\%) in the intestinal mucosa (Figure 5).

\section{Discussion}

In recent years, increasing number of publications has indicated that stress plays a major role in the gastrointestinal pathophysiology. ${ }^{[10]}$ Stress-related functional

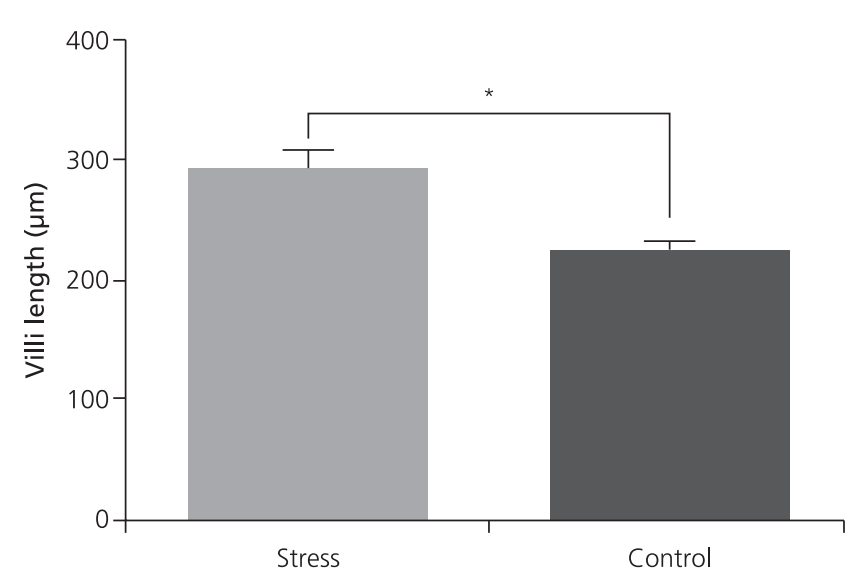

Figure 3. Comparison of villi lengths. The mean lengths of villi are significantly higher in the stressed animals than those of the control $\left({ }^{*} p<0.01\right)$. 
intestinal diseases are becoming more common in modern human life, almost like the flue infections. Both of these are the most frequently seen causes of the labor loss due to the illness. ${ }^{[1]}$ Experimental studies showed that after repetitive stress exposure, gastrointestinal inflammation is activated. ${ }^{[12]}$ The influence of stress on the clinical course of some intestinal diseases, e.g. irritable bowel syndrome (IBS) a highly prevalent disorder in developed countries, is increasingly being recognized, but the underlying mechanisms are largely unknown. ${ }^{[12-15]}$ Evidence from several studies indicate that mucosal mast cells play an important role in the stress related intestinal diseases, possibly by activating neurons that release corticotropin-releasing hormone and/or acetylcholine. ${ }^{[15]}$ The main function of the intestinal mucosa is to exchange the nutrients with waste products between intestinal lumen and blood. ${ }^{[11]}$ Epithelial cells act as a physical and functional barrier that limits the uptake of luminal antigens and pathogens. ${ }^{[12]}$ Mast cells play an important role in the regulation of epithelial transport in both human and rodent intestine and there is clear evidence that nerve and mast cell interactions are responsible in intestinal epithelial dysfunction. ${ }^{[12]}$

Mast cells are effector cells of the immune system, found principally in all organs and vascularized tissues which are in contact with the outer environment ${ }^{[16]}$ and regulate adaptive and innate immunity ${ }^{[16,17]}$ Mast cells could be seen in the skin, the gastrointestinal and the respiratory tracts, and also found in the peritoneum and synovium. ${ }^{[16]}$ They are highly active cells of hypersensitivity reactions and allergic disorders, as seen in the allergic or parasitic inflammations. ${ }^{[13,18]}$ Mast cells produce various inflammatory and immunoregulatory molecules called cytokines and chemokines. ${ }^{[18]}$ While the first identified signaling mediator molecule of mast cell is heparin, more than 200 mediators are produced by mast cells all around the body. ${ }^{[17]}$ In addition, mast cells produce biogenic amines (histamine, serotonin), interleukin (IL-1 to IL-6), leukemia inhibitory factor, tumor necrosis factor, interferon, transforming growth factor, granulocytemicrophage colony-stimulating factor, enzymes (acid hydrolyzes, chymase, phospholipases, rat mast-cell protease I and II, trypase), lipid metabolites (prostaglandins, leukotrienes, platelet-activating factor), ATP, neuropeptides (vasoactive intestinal peptide), growth factors (nerve growth factor), nitric oxide, and heparin. ${ }^{[16]}$ These multifunctional biochemical messengers were collected in the cytoplasmatic granules of mast cells and released via a very rapid process called as degranulation. ${ }^{[10,16]}$ Mast cells are present in all tissue layers of the gastrointestinal tract. ${ }^{[13,19]}$ Human and rodent mast cells derive from

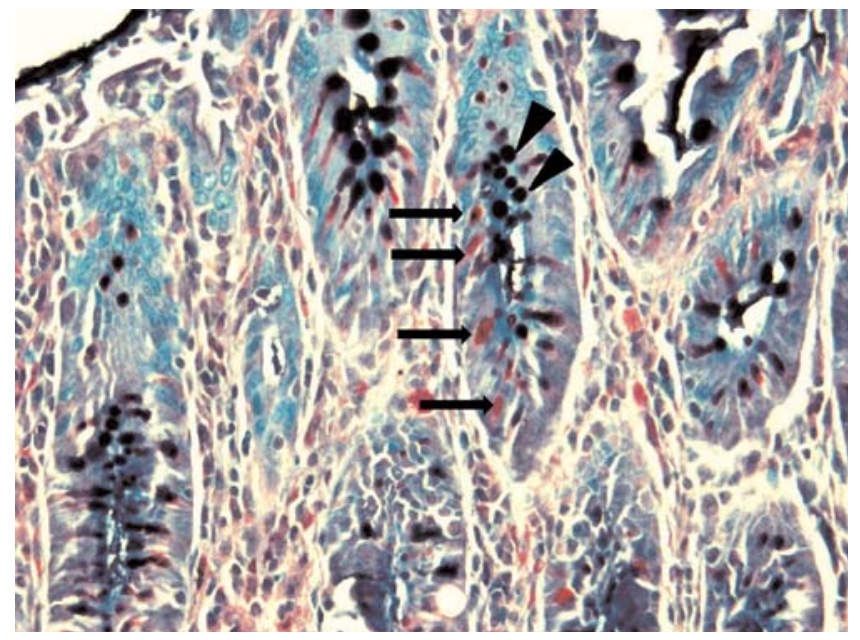

Figure 4. PAS stained histological sections showing degranulated and non-degranulated mast cells in small intestinal villi. The black arrows point the granulated and the black arrowheads indicate the non-degranulated mast cells. [Color figure can be viewed in the online issue, which is available at www.anatomy.org.tr]

pluripotent hematopoietic progenitors in the bone marrow and reach to the gastrointestinal system via the blood stream during the 16 th-22nd week of fetal life. . $^{[1,16]}$ After completing their maturation, they are mostly located in the lamina propria of the mucosal layer and in the submucosal layer. ${ }^{[19]}$ It is reported that the intestinal mucosa of irritable bowel syndrome patients contains an increased number of mast cells, also most of these patient have food allergies or adverse reactions to food. ${ }^{[10,18]}$

The pathophysiological mechanisms of chronic stress exposure on the intestinal tissue remains uncovered. ${ }^{[2]}$ Traumatic experiences during childhood have been shown

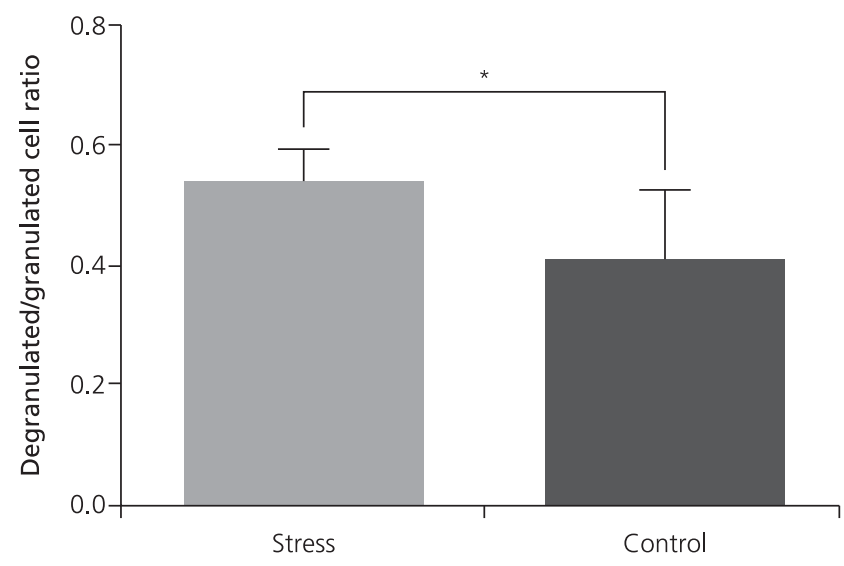

Figure 5. The ratio of degranulated/non-degranulated mast cells in stress and control groups. The stressed animals have significantly more degranulating mast cells than those of control animals $\left({ }^{*} p<0.01\right)$. 
to increase the risk of IBS development. ${ }^{[14]}$ Mast cells have been shown to play an important role in the responses of intestinal tissue to acute stressors in humans and rats. ${ }^{[2]}$ During the last decade, studies focused on mast cells and various groups have highlighted the importance of the mast cells in stress-related changes in the intestinal tract. $^{[11,14]}$ The pathological changes caused by mast cell degranulation, goblet cell secretion and endothelial cell membrane alterations in the intestinal tissue are similar to changes produced by oxidative stress. ${ }^{[11]}$ Mast cell activation results in ion transport changes in human and rat intestinal system. ${ }^{[2]}$ Researchers report that all these stressinduced abnormalities seem to rely on biological mediators released by activated mast cells. ${ }^{[4,10]}$ Thus, in adult rats, repeated stress has increased the amount of colonic mucosal mast cells, as demonstrated by using mast cell deficient rats or mast cell stabilizers. ${ }^{[14]}$ Under light microscopy, mast cells were observed in the colon of these rats, but repetitive stress exposure significantly increased the number of mast cells in the mucosa of the colon. ${ }^{[10,12]}$

Various stress models were used to evaluate the effects of stress on the gastrointestinal tract and gastrointestinal disorders. Crowding, neonatal maternal deprivation, water avoidance stress, immobilization stress, cold pain stress, acquired intestinal infection or intestinal irritation, mild environmental stress such as change of rooms are the most commonly used stress models. Researchers have demonstrated that a mild environmental stress affects the intestinal mucosa by increasing the degranulation of mucosal mast cells, the activation of goblet cells and altering the capillary endothelial ultrastructure ${ }^{[11,13]}$ It is reported that crowding is reproducing naturalistic psychosocial stress. All these single acute or repetitive homotypic stress models affect the intestinal pathobiology such as increased ion secretion and permeability, inflammation, visceral hypersensitivity and bacterial penetration. ${ }^{[4]}$ Stress has been shown to reactivate colitis in animal models. There are evidences that severe physical stress can cause gastrointestinal dysfunction and pathology. The central nervous system has the ability to modulate intestinal mast cell activity and that mast cells play a role in stress-related gut mucosal dysfunction. ${ }^{[15]}$ The proximity of degranulated mast cells to enteric glia has suggested that stress activates the enteric nervous system and attracting and activating mast cells. In stressed rats gastrointestinal mucosal mast cells were observed as hyperplastic. Stress causes epithelial barrier defects and mucosal mast cell activation in rats. ${ }^{[17]}$

\section{Conclusion}

In this study, animals exposed to chronic unpredictable stress protocol for 21 days displayed a significant increase in the number of degranulating mast cells in the intestinal mucosa. In addition, villus length of stressed animals was significantly higher than the controls. It is known that degranulation of mast cells causes releasing of various chemical mediators, neutral proteases, a group of growth factors and vasoactive intestinal polypeptide. Therefore, structural changes detected in the villi might be associated with these mediators released by activated mast cells. It is also plausible that animals exposed to stress develop an adaptation mechanism characterized by elongation of villus and deepening of crypts, which increases the capacity for absorption and digestion per unit length.

\section{References}

1. Söderholm JD, Yang PC, Ceponis P, Vohra A, Riddell R, Sherman PM, Perdue MH. Chronic stress induces mast cell-dependent bacterial adherence and initiates mucosal inflammation in rat intestine. Gastroenterology 2002;123:1099-108.

2. Santos J, Benjamin M, Yang PC, Prior T, Perdue MH. Chronic stress impairs rat growth and jejunal epithelial barrier function: role of mast cells. Am J Physiol Gastrointest Liver Physiol 2000;278: G847-54.

3. Tache Y, Martinez V, Wang L, Million M. CRF1 receptor signaling pathways are involved in stress-related alterations of colonic function and viscerosensitivity: implications for irritable bowel syndrome. $\mathrm{Br}$ J Pharmacol 2004;141:1321-30.

4. Vicario M, Guilarte M, Alonso C, Yang P, Martínez C, Ramos L, Lobo B, González A, Guilà M, Pigrau M, Saperas E, Azpiroz F, Santos J. Chronological assessment of mast cell-mediated gut dysfunction and mucosal inflammation in a rat model of chronic psychosocial stress. Brain Behav Immun 2010;24:1166-75.

5. Larsen MH, Mikkelsen JD, Hay-Schmidt A, Sandi C. Regulation of brain-derived neurotrophic factor (BDNF) in the chronic unpredictable stress rat model and the effects of chronic antidepressant treatment. J Psychiatr Res 2010;44:808-16.

6. Willner P. Validity, reliability and utility of the chronic mild stress model of depression: a 10-year review and evaluation. Psychopharmacology (Berl) 1997;134:319-29.

7. Groot Kormelink T, Arkesteijn GJ, van de Lest CH, Geerts WJ, Goerdayal SS, Altelaar MA, Redegeld FA, Nolte-'t Hoen EN, Wauben MH. Mast cell degranulation is accompanied by the release of a selective subset of extracellular vesicles that contain mast cellspecific proteases. J Immunol Epub 2016;197:3382-92.

8. Bradding P, Holgate ST. Immunopathology and human mast cell cytokines. Crit Rev Oncol Hematol 1999;31:119-33.

9. Galli SJ, Kalesnikoff J, Grimbaldeston MA, Piliponsky AM, Williams CM, Tsai M. Mast cells as "tunable" effector and immunoregulatory cells: recent advances. Annu Rev Immunol 2005;23:749-86.

10. Yang PC, Jury J, Söderholm JD, Sherman PM, McKay DM, Perdue $\mathrm{MH}$. Chronic psychological stress in rats induces intestinal sensitization to luminal antigens. Am J Pathol 2006;168:104-14.

11. Wilson LM, Baldwin AL. Environmental stress causes mast cell degranulation, endothelial and epithelial changes, and edema in the rat intestinal mucosa. Microcirculation 1999;6:189-98.

12. Santos J, Yang PC, Söderholm JD, Benjamin M, Perdue MH. Role of mast cells in chronic stress induced colonic epithelial barrier dysfunction in the rat. Gut 2001;48:630-6. 
13. Santos J, Guilarte M, Alonso C, Malagelada JR. Pathogenesis of irritable bowel syndrome: the mast cell connection. Scand J Gastroenterol 2005;40:129-40.

14. Barreau F, Ferrier L, Fioramonti J, Bueno L. New insights in the etiology and pathophysiology of irritable bowel syndrome: contribution of neonatal stress models. Pediatr Res 2007;62:240 5.

15. Söderholm JD, Perdue MH. Stress and gastrointestinal tract. II. Stress and intestinal barrier function. Am J Physiol Gastrointest Liver Physiol 2001;280:G7-13.

ORCID ID:

U. Çorumlu 0000-0001-9598-0221;

O. Ö. Aydın 0000-0003-4959-8982;

E. Ulupınar 0000-0001-9684-5937

deomed。
16. Skaper SD, Giusti P, Facci L. Microglia and mast cells: two tracks on the road to neuroinflammation. FASEB J 2012;26:3103-17.

17. Afrin LB, Khoruts A. Mast cell activation disease and microbiotic interactions. Clin Ther 2015;37:941-53.

18. Barbara G, Stanghellini V, De Giorgio R, Corinaldesi R. Functional gastrointestinal disorders and mast cells: implications for therapy. Neurogastroenterol Motil 2006;18:6-17.

19. Yu LC, Perdue MH. Role of mast cells in intestinal mucosal function: studies in models of hypersensitivity and stress. Immunol Rev 2001;179:61-73.

Correspondence to: Ufuk Çorumlu, MD, PhD

Eskişehir Osmangazi University, Faculty of Medicine,

Department of Anatomy, Meselik Campus, Eskişehir, Turkey

Phone: +90 5354558785

e-mail: ufukcorumlu@gmail.com

Conflict of interest statement: No conflicts declared.

This is an open access article distributed under the terms of the Creative Commons Attribution-NonCommercial-NoDerivs 3.0 Unported (CC BY-NC-ND3.0) Licence (http://creativecommons.org/licenses/by-nc-nd/3.0/) which permits unrestricted noncommercial use, distribution, and reproduction in any medium, provided the original work is properly cited. Please cite this article as: Çorumlu U, Aydın OÖ, Ulupınar E. Effects of chronic unpredictable stress on intestinal morphology in Wistar rats. Anatomy 2019;13(1):27-32. 